\title{
Impact of digital marketing development on entrepreneurship
}

\author{
Kenzhegul Bizhanova ${ }^{*}$, Arafat Mamyrbekov ${ }^{1}$, Ilkhom Umarov ${ }^{1}$, Akmaral Orazymbetova $^{1}$, \\ and Aziza Khairullaeva ${ }^{2}$ \\ ${ }^{1}$ Al-Farabi Kazakh National University, 050040, Almaty, Kazakhstan \\ ${ }^{2}$ Kazakh Innovative Humanitarian-Juridical University, 11, Mangilik el str, Semey, Kazakhstan
}

\begin{abstract}
The article discusses the impact of digital marketing on modern entrepreneurship, as well as the main tasks in the formation of the business structure. Predictions of rising consumer power in the digital age leading up to the turn of the century were bolstered by the advent of the Internet and then reignited by social media. Changes in consumer behavior require firms to rethink their marketing strategies in the digital sphere. Currently, much of the related research focuses more on the client than the firm. This study uses the firm's perspective to facilitate understanding of digital marketing and the use of social media, as well as its benefits and inhibitors. The second generation of Internet applications enhances marketing efforts by allowing firms to introduce innovative forms of communication and co-create content with their customers. Firms ' participation in digital marketing can be classified according to the perceived benefits and uses of digital marketing. To improve engagement with digital marketing, marketers need to focus on relationship-based interactions with their customers. This article demonstrates how some firms are already achieving just that.
\end{abstract}

\section{Introduction}

One of the biggest changes in human interaction is the recent spread of social media. The rapid growth of web-based platforms that facilitate social behaviour on the Internet has significantly changed the nature of human activity, environment and interaction [1]. Real social relationships have been transferred to the virtual world, which has led to the creation of online communities of people from all over the world. This movement into the digital dimension allows people to share knowledge, entertain each other and promote dialogue between different cultures [2].

\footnotetext{
* Corresponding author: doptaganka@yandex.ru
} 
Entrepreneurship was established and developed at a late stage of capitalism, when it was singled out as the fourth factor of production. The reason for this was the awareness of economists of the decisive factor of entrepreneurship in the progress of the economy. In spite of a rather short period of time, this factor of production, today, is popular and rapidly developing. The goals of any business entity in the long run are to maximize profits and minimize the cost of own production, as well as to meet the needs of buyers [3].

The relevance of this article is due to the fact that the penetration of the Internet in all aspects of human life has led to a change in the traditional regulation of business structures.

Digital marketing is based on online channels with the highest frequency of use, they are dynamic, they can change from year to year and are always influenced by market trends. In short, digital marketing constantly uses review, analysis, explanation, promotion process and helps to establish stronger brand-consumer relationships, helping to effectively identify consumer relationships and attract attention. The impact of this type of unconventional marketing has been great, affecting sales and the number of customers, dictating, at best, commercial tendencies.

If most clients interact with social media, firms should also interact with social media. In the past, marketers have used email, direct marketing, telemarketing, information websites, television, radio and other mechanisms to disseminate information related to the firm or its products. The World Wide Web has been used to present marketing messages through page views and advertising to reach large numbers of people in a short period of time. It served as an advertising tool that shaped surfer behaviour [4].

Living in the digital age, when everyone has access to the Internet, it is logical to switch to this type of marketing and intensive use of companies. The emphasis is on the following factors: reputation management, which consists in making a decision based on customer feedback, which is evaluated by the company and then assimilated; full presentation of services, the consumer is initially attracted by the type of bait, the next step will be to present him a full set of specific source of search information; communication is a key element, as a specific monologue of the campaign initiated by the company is removed and the dialogue is established through social platforms; brand recognition [5]

\section{Literature review}

Transforming communication channels is a complex task for all industries, but especially for communication and marketing industries. As Malhern notes, "Digitization of the media represents a phase shift in the history of communications. [6].

According to Fader (2012), the 1990s were a decade of e-commerce, and the beginning of the 21st century was an era of social commerce. The role of "digital marketing" is confirmed by IBM's research, which consists of interviews with CMOs (IBM Institute for Business Value, 2011). These WSCs articulate the following four biggest challenges: data explosion (sometimes also called big data), social media, channel proliferation, and changing consumer demographics. Three of these four biggest challenges correspond to the development of digital marketing. [7, 8].

According to Kung, changes in technology and consumer behavior have always been key factors in changing media strategy. 9] However, how these elements differ and are therefore complex. It is important to have a clear understanding of what we mean by "digital marketing".

Professor George Day of Wharton has identified a growing gap between the accelerating complexity of markets and the ability of most marketing organizations to understand and cope with this complexity. While market fragmentation and rapid change forces are everywhere, we believe that the use of the Internet is a major driver of widening the gap. [10] 
The Institute of Digital Marketing (DMI) defines digital marketing as "the use of digital technology to create integrated, targeted and measurable communication that helps to acquire and retain customers in building deeper relationships with them" [11]. Simply Digital Marketing defines the term as follows "Digital marketing is a sub-sector of traditional marketing and uses modern digital channels to host products, such as downloadable music, and primarily to communicate with stakeholders, such as customers and investors, about the brand, products and business progress. Both definitions are useful; the first is because it highlights the importance of a strategic framework for any marketing approach, i.e. its measurability and integration, as well as its focus on relationships and communication. The second definition serves as a reminder that any use of digital marketing must be effective in promoting products or services, as well as include intellectual strategy and excellent communication. It is also useful to clarify the intended meaning of other terms used in this document. The term "creative industries" is commonly understood to include publishing, media (e.g. television and radio), architecture, craft and design, fashion, advertising, public relations, and computer games and software as defined by the U.S. Department of Media Culture and Sports. [12]

According to Jamal, the Internet has become one of the most important markets for goods and services transactions. For example, consumer spending in the U.S. Internet has exceeded $\$ 100$ billion (already in 2007), and online demand for information products such as books, magazines and software is growing at a rate of $25 \%$ to $50 \%$ [13].

Social media provide marketing professionals with excellent opportunities to reach consumers in their social communities and build more personal relationships with them [14].

Social media have changed the way a brand's content is created, distributed and consumed, transferring the power to shape the brand image from marketers to online communications and consumer content [15].

According to Andrew T. Stefan, the use of the Internet, social media, mobile applications and other digital communication technologies has become part of the daily lives of billions of people. For example, the current level of Internet usage among adult Americans is about $87 \%$, approaching $100 \%$ for demographic groups such as adults with higher education and higher incomes. People are increasingly exposed to digital and social media. This is done for many purposes, including in their role as consumers, as they seek information about products, buy and consume them, and communicate with others about their experiences. Marketers have responded to this fundamental shift by increasing the use of digital marketing channels. In fact, by 2017 , about a third of global advertising spending is projected to be on digital channels.

According to Andreas M. Kaplan, "mobile marketing is any marketing activity carried out through a ubiquitous network to which consumers are constantly connected through a personal mobile device".

In the book "Digital Marketing: The Essential Guide to New Media and Digital Marketing", Kent Wertime and Jan Fenwick talk about how blogs and social networks can promote their brand and increase sales. Here's a quote from the book: "Advertising needs to be placed where consumers' attention is focused. In the age of the Internet and digital devices, people are spending more and more time in virtual space - and this must be taken into account by all marketers".

According to S. Ziyadin, the most popular way to promote products and services in any sphere is marketing in the global Internet. 


\section{Methodology}

Statistical and economic analyses were used as sources of secondary information. In departmental bodies the basic data on the researched market of production in the Republic of Kazakhstan have been received. For consideration of influence of digital marketing on business As sources of the secondary information the statistical data of the Kazakhstan Association of Internet business and mobile commerce are considered.

\section{Discussion and results}

Growing digitalization is causing serious problems for marketing executives. They face growing, complex and rapidly changing markets that are beyond their control. As a result, firms have realized these changes and how to cope with them [10].

Interaction between market participants in the Internet market takes the following variants - models of interaction between market participants. Let us classify these models in Table 1.

The B2B model allows to optimize the activity of related enterprises, and also accelerates the sale and purchase of goods necessary for the enterprise.

B2C model optimizes the capabilities of the enterprise in terms of expanding sales opportunities, in turn, the consumer saves time without moving in space, in addition, having the option of preliminary selection of goods.

The G2E model optimizes the efficiency of public authorities, especially the government's public service delivery system. In addition, direct communication of individuals and legal entities with the state authorities levels corruption, as transparency (openness) of operations is ensured.

Table 1. Classification of the main models of interaction between market participants.

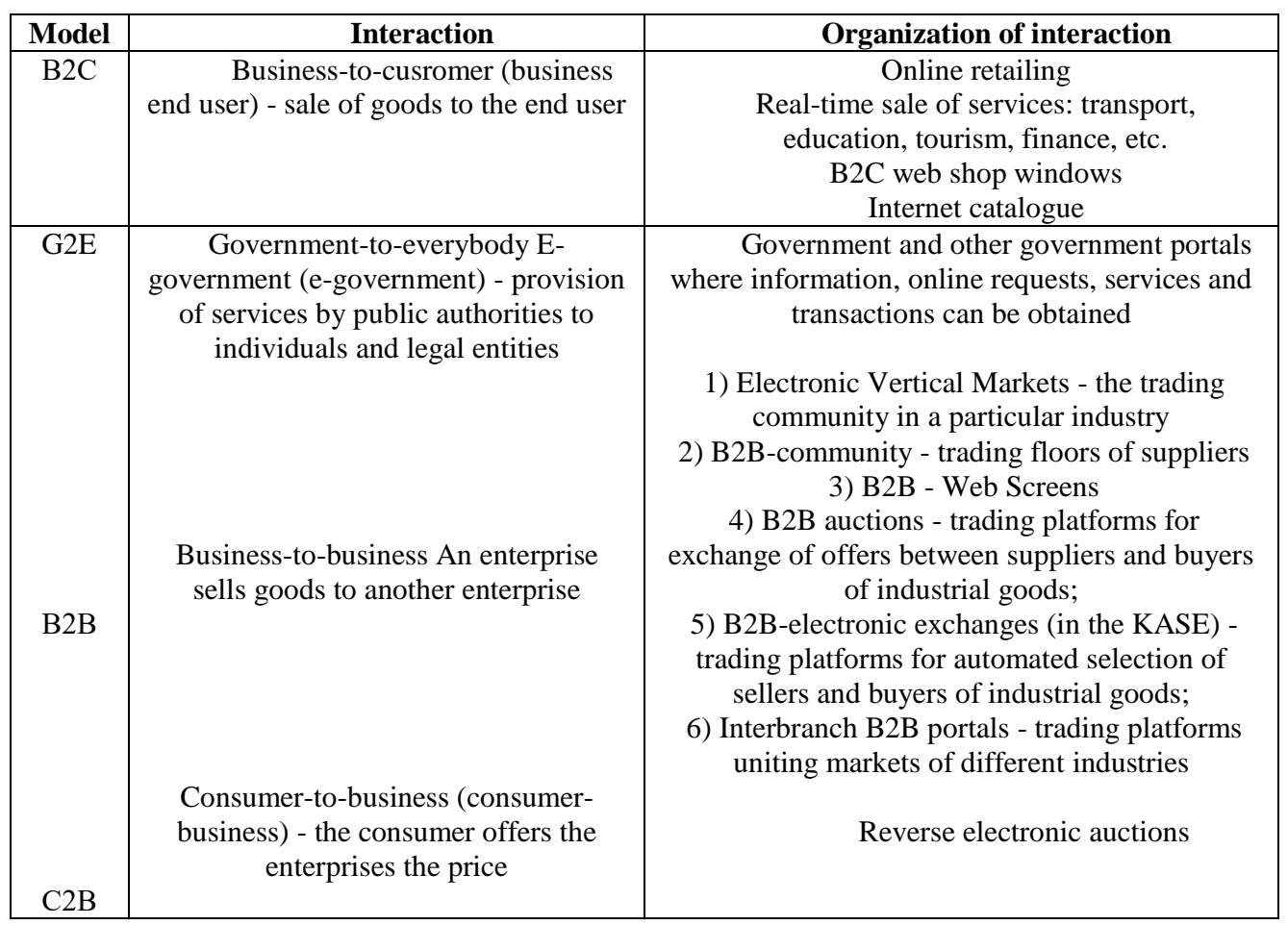


Let's define the areas of application of information technologies in the organization of business processes:

1. Providing information by creating databases of offered products, vacancies, prices, etc;

2. Internet communications - organization of videoconferences, as well as the use of Internet telephony to manage business processes at a distance;

3. Internet media (media outlets) - providing information to market participants;

4. Internet-education-distance learning, testing and digital library services;

5. Internet advertising and PR- corporate and departmental sites and blogs, promotional sites (demonstration sites), development of advertising networks and a special platform for social, political and commercial advertising;

6. Global automated process control systems (APCS): MES (Manufacturin Execution System) in production; ERP (Enterprise Resource Plannin) and CRM (Customer Relationship Management) systems in business;

7. e-commerce through electronic means of communication;

8. e-government - organization of interaction between the state and information and communication technology market participants.

Table 2. Advantages and disadvantages of e-commerce for various participants of economic relations

\begin{tabular}{|c|c|c|}
\hline Comparison & Consumer & Manufacturer \\
\hline Advantages & $\begin{array}{c}\text { Ubiquity (consumers can satisfy their } \\
\text { demand anywhere) } \\
\text { Wide range of products } \\
\text { Anonymity }\end{array}$ & $\begin{array}{c}\text { Reduced costs (promotion costs will } \\
\text { be lower if they are online) } \\
\text { Globality (potential consumer base is } \\
\text { located all over the world) }\end{array}$ \\
\hline Disadvantages & $\begin{array}{c}\text { Lack of trust in Internet services } \\
\text { It is impossible to assess the quality of } \\
\text { the product } \\
\text { possible difficulties and losses in } \\
\text { returning goods }\end{array}$ & $\begin{array}{c}\text { Problems of legalization and } \\
\text { regulation of activities on the Internet }\end{array}$ \\
\hline
\end{tabular}

Nowadays large corporations transfer business processes to the network, which allows to reduce not only the costs, but also time from the origin of the idea to its implementation. As for the possibilities of using information technologies by Kazakhstani enterprises, there are a number of obstacles here.

First, for successful implementation of e-commerce, electronic enterprises are required, and the degree of automation of business processes at Kazakhstani enterprises remains at a low level. Complex structure of ERP (enterprise resource plannin) - a conductor of the system is an expensive product that can afford the subdivisions of industrial enterprises of the Republic of Kazakhstan.

Secondly, only those industrial enterprises that are interested in expanding the range of potential customers or choosing suppliers may be interested in e-commerce, but the search for contractors in Kazakhstan is limited to monopolization of production in some areas and the relatively risky nature of the economy.

Third, Internet business is more efficient if it is carried out on the basis of an electronic trading platform, i.e., on the basis of exchange traditions that are in their infancy and development in Kazakhstan.

Thus, it can be concluded that online trading in the B2B model is beneficial to Kazakhstan in industries where competition is developed, the degree of standardization of products (stock exchange trading conditions) is high and there are significant financial opportunities. The main problems of B2C model development are relatively small number of Internet users, the scale of Internet usage and the factor of mentality of Kazakhstani consumers who do not trust Internet shops because of inertia and preference of traditional 
distribution channels, as well as underdevelopment of the service of Kazakhstani Internet shops and the aspect of security of transactions in the network.

The main problems of the $\mathrm{B} 2 \mathrm{C}$ model development are relatively small number of Internet users, the scale of Internet use and the factor of mentality of Kazakhstani consumers who do not trust online shops because of the inertia and preference of traditional distribution channels, as well as underdevelopment of the service of Kazakhstani online shops and the aspect of security of transactions in the network.

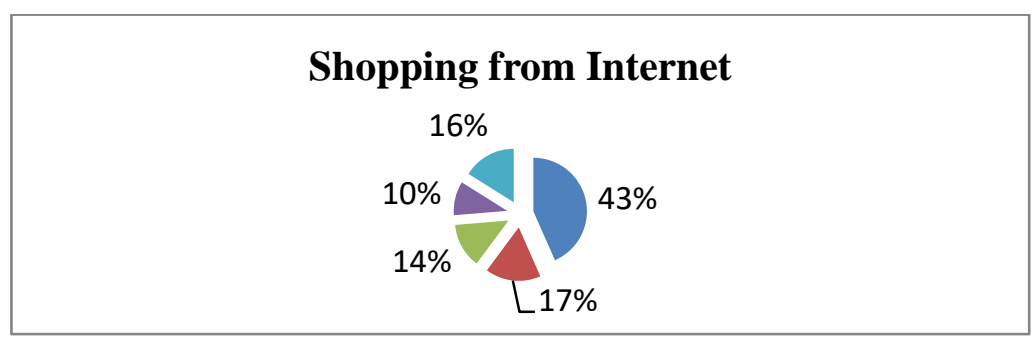

Fig. 1. Shopping at online stores [21].

In particular, out of the total number of Internet users $73.29 \%$ of users make purchases in online stores; the structure of purchases is dominated by the order of air and rail tickets (45.39\%), also through the network consumers buy clothes $(14.76 \%)$, computers and digital equipment (13.54\%), household appliances (10.23\%) and other goods (more than $16.08 \%$ ).

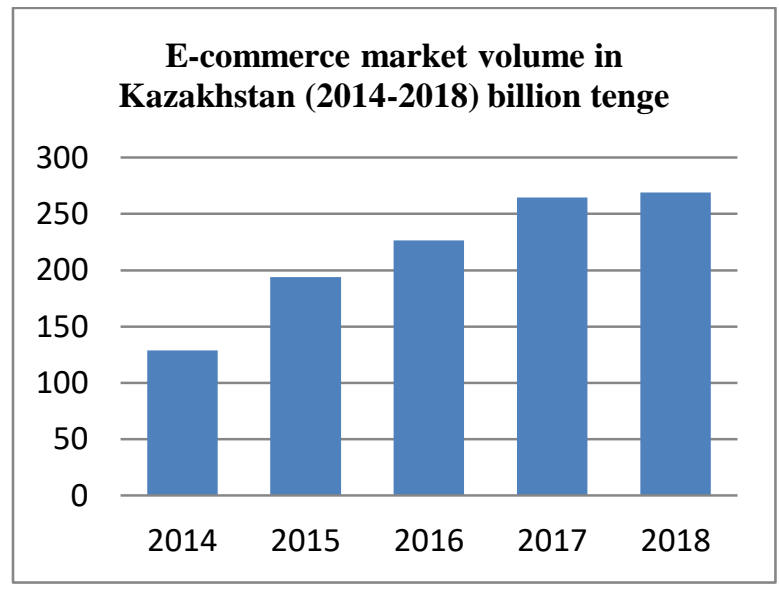

Fig. 2. E-commerce market volume in Kazakhstan (2014-2018) billion tenge

According to the data of the Kazakhstan Association of Internet Business and Mobile Commerce, the volume of the e-commerce market amounted to 129 billion tenge, in 2015165 billion tenge. That is, the capacity of the e-commerce market increased by $50 \%$.

In 2016, the market volume amounted to $\$ 226.4$ billion in 2017-264.52 billion tenge. According to the latest statistics, the e-commerce market volume in 2018 amounted to 269 billion tenge. Thus, we can see that over the past five years, the e-commerce market has grown significantly.

In the present era, that is, at present, even if the term does not have a clear definition, it plays an active role in the socio-social and production relations of countries striving for civilization throughout the world. 


\section{Conclusions}

Digital marketing is based on internet channels with the highest frequency of use, which are dynamic, they can change from year to year and are always influenced by market trends. In particular, digital marketing uses regular review, analysis, interpretation, promotion process and helps to establish strong consumer-brand relationships. The impact of this type of unconventional marketing has been enormous, affecting sales and the number of customers, at best the commercial processes.

As a result, we can highlight a number of features of digital marketing in the formation and development of the business structure:

1) Attracting the attention of a large target audience: this process can be carried out through a set of techniques of Internet marketing aimed at targeting customers through a specific type of information. In the scientific literature there are widely presented ways in which there is an opportunity to attract the attention of buyers. For example, SEO promotion, Email - mailing list, contextual advertising, advertising in social networks, etc;

2) Increase in the number of sales: Internet marketing causes the emergence of ecommerce, which at times facilitates the process of purchasing goods and services, as the purchase is carried out through online stores, where all the necessary information about the various products of the company or company;

3 ) determines the directions of competition: Internet marketing sets a goal to identify competitors in the market structure, determines the nature of their behavior in competitive conditions and is a mechanism to stimulate the development of this competition to optimize and improve production;

4) does not require high material and financial resources: Internet marketing implies an effective mechanism to bring the product to consumers through targeting in the virtual environment, but is a budgetary one in use, because the main work is carried out directly on the Internet with the involvement of a small number of employees.

\section{References:}

1. R. T. Rust, Inte. J. Res. Mark (2019)

2. M. T. P. M. B. Tiago, J. M. C. Veríssimo, Bus. Hor., 57(6), 703-708. (2014)

3. A. Y. Anisimov, The role of Internet marketing in modern entrepreneurship. Humanitarian scientific research (2017)

4. P. R. Berthon, K. Plangger, D. Shapiro, Bus. Horiz., 55(3), 261-271 (2012)

5. O. D. Negoiţă, A. A. Purcărea, M. A. M. Popescu, Procedia Manufacturing, 32, 1043 1050 (2019)

6. Mulhern, F. J. Mark. Comm., 15(2-3), 85-101 (2009)

7. P. S. Fader, R. S. Winer, Mark. Scie., 31(3), 369-371 (2012)

8. IBM CMO C-suite Studies. (2011)

9. L. Kung, Strategic management in the media: Theory to practice (2008)

10. G. S. Day, J. Mark., 75(4), 183-195 (2011)

11. C. Wymbs, J. Mark. Educa., 33(1), 93-106 (2011)

12. J. Royle, A. Laing, Int. J.1 Inf. Man., 34(2), 65-73. (2014)

13. P. Albuquerque, P. Pavlidis, U. Chatow, K. Y. Chen, Z. Jamal, Mark. Sci., 31(3), 406432 (2012)

14. L. Kelly, G. Kerr, J. Drennan, J. Int. Adv., 10(2), 16-27 (2010)

15. W. H. S. Tsai, L. R. Men, J. Inte. Adv., 13(2), 76-87 (2013) 